\title{
FORMAÇÃO AO LONGO DA VIDA (FLV) NA DOCÊNCIA: PERSPECTIVAS E INTERESSES DO PROFESSOR RUMO À CONSOLIDAÇÃO DE COMPETÊNCIAS PROFISSIONAIS
}

\author{
LIFELONG TRAINING (LLT) IN TEACHING: TEACHERS' PERSPECTIVES AND \\ INTERESTS TOWARDS THE CONSOLIDATION OF PROFESSIONAL SKILLS
}

\author{
M. E. de OLIVEIRA ${ }^{1 *}$, V. A. PARREIRAS ${ }^{1}$ \\ 1 Centro Federal de Educação Tecnológica de Minas Gerais - CEFET-MG, Programa de Pós- \\ Graduação em Estudos de Linguagens, Brasil
}

\author{
ARTICLE INFO \\ Article history: \\ Received 2018-07-02 \\ Accepted 2018-08-17 \\ Available online 2018-08-31
}

*Autor correspondente:

E-mail:mateus2012_ita@hotmail.com
Palavras-chave: Formação ao Longo da Vida, Consolidação de competências profissionais, Autonomia.

Keywords: Lifelong education. Consolidation of professional skills. Autonomy.

RESUMO. O presente trabalho resulta da necessidade de destacar o profissional da educação, o professor, como ator-chave de seu plano de crescimento pessoal e profissional, desconsiderando as pressões exteriores, frequentemente, fruto de um sistema educacional cada vez mais movido pela força do capital, para dar visibilidade às aspirações e anseios por conhecimento dos próprios educadores. Mesmo que a procura por formação contínua possa se relacionar intimamente com ganhos financeiros por meio de titulações acadêmicas, busca-se aqui, ir de encontro a narrativas de docentes que tenham ciência do que desejam aprender e que se dedicam a este ideal, o que por vezes reflete diretamente na consolidação de competências profissionais que dialoguem harmoniosamente com suas práticas pedagógicas, contribuindo com o sucesso do corpo discente e da instituição que atua. Diante disso, no contexto contemporâneo das Tecnologias Digitais da Informação e da Comunicação - TDIC, é inevitável considerar o papel que as tecnologias da aprendizagem têm desempenhado nos cursos de formação continuada para professores, imprimindo muito mais rapidez e dinamicidade ao processo de aprendizagem. Este artigo traz algumas reflexões iniciais a respeito dessas questões e foi produzido a partir de uma pesquisa mais ampla e em andamento na linha de pesquisa III, Linguagem, Ensino, Aprendizagem e Tecnologia, do Programa de Pós-Graduação Stricto Sensu (Mestrado) em Estudos de Linguagem do CEFET-MG - POSLING. A nossa expectativa é a de contribuir com o debate sobre formação docente ao longo da vida e com a promoção de autonomia de professores em serviço ao longo da vida e da carreira. 
ABSTRACT. The present article results from the need to emphasize the educator as a professional, the teacher, as the key actor in his or her personal and professional growth plan, disregarding external pressures, often the result of an education system increasingly force-driven of the capital, to give visibility to the aspirations and longing for knowledge of the educators themselves. Even if the demand for continuing education can be intimately related to financial gains through academic qualifications, it is sought here, to meet the narratives of teachers who are aware of what they want to learn and who are dedicated to this ideal, which times reflects directly in the consolidation of professional competences that dialogue harmoniously with their pedagogical practices, contributing to the success of the student body and the institution in which they act. In the contemporary context of the Digital Technologies of Information and Communication - DTIC, it is inevitable to consider the role that learning technologies have played in continuing education courses for teachers, imparting much more speed and dynamism to the learning process. This article brings some initial reflections on these issues and was produced from a broader and ongoing research in the research line III focusing on Language, Teaching, Learning and Technology, at the Stricto Sensu Postgraduate Program in Languages Studies at CEFET-MG - POSLING. Our expectation is to contribute to the debate on lifelong teacher education and to the promotion of autonomy for in-service teachers throughout their lives and careers.

\section{A importância da formação ao longo da vida}

As construções relacionadas ao mundo da educação trabalham sua exposição por meio do pensar, do conviver, do ser e do discernir ao longo da vida (LIBANIO, 2002). Logo, é justo reconhecer que os programas de formação dos profissionais docentes devem acompanhar essa linha, a fim de oferecer professores que contribuam singularmente na vida de seus alunos. Dessa forma, com as constantes adaptações que afetam as relações no universo educacional, a presença de um professor formador que saiba articular bem a linguagem empregada a fim de torná-la prática constante da sua atuação em sala de aula, instrumento eficaz com vista à aprendizagem, com preocupação inerente ao ensino por meio de tecnologias coerentes torna-se fundamentalmente urgente. Com isso, além dos cursos de licenciatura, o docente pode procurar intensificar a busca por novas competências profissionais através da Formação ao Longo da Vida aplicada ao professor que constitui assunto principal deste projeto de pesquisa.

Pode-se entender, a princípio, o percurso formativo ao longo da vida como um eixo da formação contínua que emerge das aspirações do próprio indivíduo em sua plena liberdade de decisão. Nesta perspectiva, o indivíduo que escolhe investir em tal caminho profissional, não o faz com vista à adaptação para servir a modelos pré-estabelecidos pelo mercado de trabalho ou sistemas de ensino, apesar de haver inegáveis semelhanças pela corrida na vantagem profissional. Contudo, preocupa-se intensamente com um plano de vida maior, em conseguinte, a necessidade de oferecer ao seu ambiente de ensino novas competências e habilidades.

Desse modo, em um mesmo programa de formação continuada para docentes, é 
visivelmente comum encontrar educadores que estejam caminhando ao encontro de seu projeto de vida e outros que apenas se interessam pelas vantagens profissionais que um novo certificado ou diploma pode conceder. Em ambos os casos, não interessa a este trabalho julgar quem está sendo certo ou errado, uma vez que os benefícios de uma nova titulação, inclusive os financeiros, poderão ser sentidos pelos dois grupos. Entretanto, interessa aqui, os professores que possuem motivações mais profundas e que se apresentam em paralelo com sua autonomia de escolha, pois é a esses em que se aplica a noção de formação ao longo da vida.

Diante disso, tomando como referência agora os canais utilizados para formação continuada, destaca-se a disseminação da cultura da informação que, por sua vez, promove outro aspecto à estrutura dos cursos oferecidos aos professores, sendo que, é ascendentemente apreciada a velocidade com que novas informações percorrem a esfera acadêmica e social, tornando não mais obrigatória a presença do aluno a um banco universitário. Por esse meio, o professor contemporâneo pode atualizar-se e formar-se por intermédio da tecnologia informacional. Hoje, através de sólidas ferramentas de ensino a distância, consegue refletir e acompanhar os educandos que, por vezes, já cresceram em um recente mundo de acesso virtual aos saberes.

Mas, como se daria esse processo de educação e formação que acompanharia o indivíduo, em especial o professor, por toda sua vida? Como se apresenta o aperfeiçoamento de competências do professor que busca desenvolver-se por necessidade própria e íntima? Quais exemplos de FLV bem sucedidos podem ser tomados como referência e investigados? Quais efeitos são causados pela carência na formação de docentes? O que esta impacta no sucesso do mestre, do aluno e da escola? São questões assim como essas que servem para iniciar reflexões a respeito da formação ao longo da vida no universo professoral a qual implica na posição do sujeito como fator primordial de seu plano de crescimento profissional e pessoal.

Nesse momento, as pressões exteriores como crises financeiras e acumulação de capital são deixadas de lado para que o próprio ser humano possa se ver como agente ativo e constituinte de seu desenvolvimento. Então, a Formação ao Longo da Vida (FLV) parte da premissa de que o educando é o protagonista do seu percurso educativo (FERREIRA, 2012). Sendo que o acesso ao conhecimento permite o desenvolvimento da pessoa humana, mesmo que os saberes que ela busca não sejam de interesse do mercado de trabalho no momento atual.

Da mesma forma, as práticas educativas aqui presentes baseiam-se na necessidade de conduzir o trabalhador/professor a encontrar respostas para questões latentes que surgem 
ao longo da sua prática social e profissional (MERLE, 2006). Sem contar na busca interminável pelo conhecimento por parte da pessoa em todos os níveis de sociedade o que, por sua vez, culmina com a participação crítica da população nas mais diversas esferas sociais.

Logo, observa-se a relevância desse estudo, uma vez que, a velocidade e a complexidade com que o mundo do trabalho se apresenta, o modelo de gestão baseado nas competências dos indivíduos toma posição de pleno destaque (DUGUÉ, 2004). Sendo que, o contínuo movimento dos saberes confere desempenho diferenciado que se evidencia em momentos de crise, ou seja, quando rotinas de trabalho são desestabilizadas, traduzidas na forma de problemas inesperados que podem germinar em qualquer momento e situação (PIRES, 2002).

Todavia, em sentido contrário à proposta de FLV aplicada ao contexto do professor, incluem-se os programas rasos de qualificação profissional que se preocupam apenas em ofertar um diploma capaz de conceder vantagens competitivas ao docente nos momentos de seleção, seja em escolas particulares ou públicas por meio de designações. Portam currículos extremamente simples e avaliações com pouco sentido prático. Nesse caso, carregam, em seu âmago, profundas deficiências estruturais que interferirão negativamente na vida e formação dos alunos.

Assim, nesse modelo de qualificação, as demandas externas ao professor é que tomam lugar fundamental e primordial. Transmitem-se também as exigências do mercado de trabalho e dificultam o diálogo entre o trabalhador/professor com sua profissão. Pois, qualificase não para buscar o crescimento pessoal e profissional, mas para acumular um novo certificado curricular.

Apesar da gravidade e importância dessa questão, não constitui objetivo principal deste trabalho avançar nos estudos das possíveis consequências dessa ideologia mercadológica, mas sim ir de encontro aos componentes que impulsionam e interessam o professor na procura pela sua formação profissional, aproximando bem mais de si mesmo, das suas aspirações e de seus projetos, em um ambiente favorável a ao crescimento intelectual. Em grande medida, a percepção desses componentes é frequentemente afetada pelas instituições de qualificação profissional que se preocupam em enquadrador o educando ao cerco que o mercado impõe como sendo o exigível para obter certo sucesso no mundo do trabalho.

Nesse ínterim, não se pode apreender a Formação ao Longo da Vida como um instrumento de acesso ao conhecimento que seja construído por base apenas da atualização de alguns conceitos. Em contraponto, a formação do docente, tanto inicial quanto continuada, representa a pedra de toque de um projeto de crescimento que o professor pode traçar ao longo da sua vida, não apenas carreira, em caráter cada vez mais autônomo, conferindo 
assim, liberdade e consciência das ações e rumos que escolhe seguir. Em suma, formação essa que posiciona o cidadão na centralidade do seu projeto de constante aperfeiçoamento. Nessa direção, a identificação das suas aspirações, bem como os efeitos de todo esse esforço por parte desses profissionais da educação, constitui contribuição fundamental deste trabalho. Para isso, faz-se importante esperar, como nos propõe refletir a Formação ao Longo da Vida, que o professor já tenha em mente o que deseja aprender.

Diante dessa conjectura, a temática proposta representa importância singular na relação existente entre FLV e desenvolvimento de competências professorais no âmbito da Educação Profissional, pois, é solo fértil para o bem-estar do profissional da educação tomado como pessoa humana. Justifica-se também na maneira através da qual se apresenta à sociedade uma nova forma de encarar a formação como elemento capaz de responder às expectativas depositadas por professores que visam construir uma carreira bem-sucedida tanto no âmbito pessoal quanto no profissional.

As conclusões a cerca de tal problemática poderão servir para entender melhor como que a noção de competência profissional (trabalhada em um programa de formação no decorrer da vida do professor) se mostra importante no ambiente escolar, assim como os benefícios que, provenientes da qualidade das aulas ministradas por esses docentes participantes, podem contribuir para o desenvolvimento dos alunos.

\section{Foco do estudo}

O modo como os trabalhadores buscam se desenvolver com a finalidade de preparar terreno fértil para a evolução das técnicas e comportamentos inerentes ao ofício que praticam ocupa lugar importante no universo da educação. Assim, torna-se relevante investigar processos de formação capazes de oferecer ao sujeito ferramentas indispensáveis para seu crescimento pessoal e profissional.

Desse modo, o propósito desta pesquisa surge da importância de profissionais em geral e do professor em particular de se reconhecerem como profissionais reflexivos e em constante construção, atentos às necessidades dos seus alunos e às transformações diárias que a aprendizagem promove em cada um deles. Acrescenta-se ainda que as reflexões do docente da sua prática profissional em sala de aula contribuem essencialmente na promoção da autonomia, fator essencial no percurso formativo ao longo da vida.

Nesse pensamento, a problemática se fundamenta em investigar a relação que a FLV estabelece com a consolidação de competências por parte do professor-aluno, ou seja, entender, por meio de experiências relatadas, quais são as principais motivações pessoais 
em direção ao desenvolvimento profissional, como se constitui o surgimento e a evolução de competências do sujeito ao longo de sua formação, e como e em quais oportunidades se efetiva no decorrer da atuação em sala de aula.

Em complemento, entende-se que é na sua prática pedagógica que um professor reconhece e reflete sobre as características da sua 'matéria prima', no intuito de alterar a forma de planejar as suas atividades, estratégias e recursos pedagógicos, adequando-as continuamente, sendo um profissional que se encontra numa posição privilegiada para se questionar sobre o que precisa mudar, formular hipóteses e testá-las em contexto de sala de aula, a fim de coletar dados, interpretá-los e tomar decisões sobre que caminho escolher com vista ao sucesso das aprendizagens.

Com isso, abandona-se a ideia de que o professor é o profissional munido de conhecimento e que, devido a um dever social, está encarregado de repassar os saberes a um grupo de estudantes que estão em uma sala de aula muitas das vezes desmotivados e sem perspectivas de grandes mudanças em suas vidas e carreiras. À medida que o educando consegue assimilar, ou seja, tornar semelhante a si mesmo o conhecimento absorvido em uma aula, por meio de um sistema de cooperação entre professor-aluno, em que ambos discutem sobre problemas contemporâneos arcaicos em uma sociedade que insiste em se alterar, tanto no âmbito econômico social e político, pode-se constatar que o educador atingiu seu objetivo profissional. A Formação ao Longo da Vida coloca-se como capaz de promover esse sucesso em sala de aula, sendo que capacita o profissional e contribui para que constantemente possa se inserir em exercícios de reflexão para com sua prática diária de ensino, com rumo à melhoria contínua.

Em concordância, faz-se referência a uma investigação contínua e por toda a vida de um professor que toma para si o protagonismo do seu desenvolvimento profissional e pessoal. Ao estarem em contato direto com os alunos, aos professores cabe a responsabilidade de procurarem o que os seus alunos necessitam para atingir os objetivos a que se propuseram. Em suma, a figura do professor se apresenta como um ser capaz de estabelecer laços entre os alunos e seus projetos.

Contudo, essa não é uma tarefa trivial, na medida em que as situações problemáticas que se vivem hoje, em especial no contexto complexo e incerto do setor público, as escolas demandam grande capacidade de recursividade para intervenções, o que muitas vezes culmina em um cenário de desalento e desmotivação no trabalho de ambos os lados. "As situações que os professores são obrigados a enfrentar (e a resolver) apresentam características únicas, exigindo, portanto, respostas únicas” (Nóvoa, 1992, p. 16). Só um professor reflexivo poderá mobilizar saberes de uma situação para outra, com características específicas. Para que esta construção e "trans-formação" (Nóvoa, 1992, p. 21) do saber ocorra ao longo da vida, o diálogo e a parceria entre professores são também indispensáveis para 
consolidar práticas e os saberes que emergem dessas práticas. Assim, evitam-se as repetições de experiências fracassadas, produtos, em parte, de um sistema educacional que não consegue estabelecer vínculos profícuos entre seus agentes. Essa parceria também se caracteriza como formação ao longo da vida, no sentido que coloca o professor em ambos os papéis, o de mestre e o de aluno.

Diante do exposto acima, no contexto atual da "Sociedade da Informação", o mundo digital demanda do professor que deixe de ser o transmissor de conhecimento e comece a revelar alguma preocupação com a transição das abordagens conservadores de formação/aprendizagem, baseadas na reprodução de conhecimento, para as inovadoras, em consonância com a noção de construção de conhecimento e de saberes, na medida em que as primeiras não foram capazes de desenvolver uma educação que responda às necessidades da sociedade atual. Urge, portanto, a emergência de uma postura docente pautada pela capacidade de problematização nas complexas situações-problemas que incidem sobre sua área de conhecimento, corpo discente e prática profissional.

Neste sentido, o estudo que se propõe pode contribuir com novas análises e perspectivas de práticas pedagógicas que busquem dar voz aos alunos, colete e organize informações relativas à utilização de abordagens e metodologias de ensino que permitam promover o desenvolvimento da capacidade de argumentação e de competências eficientes à construção de saberes e também da sua própria identidade docente. Considere-se que, nesse contexto, o papel do professor é procurar identificar e compreender o que pensam os seus alunos e abordar analiticamente as dificuldades que apresentam, explorando ao máximo as potencialidades pedagógicas dos recursos disponíveis. Sabendo compreender o elenco de competências e habilidades que o educando já porta com o intuito de acrescentar novas projeções profissionais e pessoais nesse ser.

A investigação proposta aqui, portanto, incide numa das formas possíveis de diagnosticar expetativas, motivações, dificuldades, avaliar resultados, que poderá lançar luzes sobre ensinar a aprender na "Era da Informação", a partir das práticas pedagógicas dos participantes. Pretende-se, pois, discutir em que medida os professores reconhecem a importância da FLV como elemento poderoso para identificar os conhecimentos prévios dos alunos e, através deles poder estudar medidas corretivas na missão de ensinar.

\section{Formação, competência e autonomia}

A Formação ao Longo da Vida apresenta-se como elemento capaz de catalisar o aperfeiçoamento de competências sendo que inquieta o trabalhador a buscar seu próprio 
crescimento pessoal e profissional e assim, trabalhar ou mesmo adquirir novas competências. Dito isso, apresenta-se, a seguir, o suporte teórico pelo qual se orienta o tema em questão.

Num primeiro momento, é importante estabelecer o conceito de formação aqui apresentado. Souza (2013) traz o conceito de formação pautado na ideia de que é um processo pelo qual, através do trabalho, "algo ou alguém toma forma/ó" e não o processo que coloca ou submete algo ou alguém a uma "forma/ô/". Em seguida, Libanio (2002, p. 11-12) defende que o conceito do termo "formação" pode em alguns casos ser entendido como enformar, entretanto observa que o uso do verbo formar pode se apresentar de modo reflexivo, formar-se, e com isso, adquirir o sentido de "processo educativo". Ferreira (2012, p.62) ressalta a importância desse modelo para a inserção e continuidade do cidadão no trabalho em virtude do desenvolvimento de suas competências ao afirmar que "a FLV se relaciona à empregabilidade dos indivíduos por fornecer conhecimentos e meios de adquirir e desenvolver novas competências". Por sua vez, Merle (2006) já orienta que a formação de adultos, compreendida pela FLV, constitui uma "autoformação" que confere ao indivíduo mais autonomia para guiar suas ações no ofício.

Referindo-se em particular ao profissional docente, Junior e Coutinho (2007) defendem que o aperfeiçoamento da docência se dá em todos os momentos da sua existência. Por meio da experiência profissional, novos conhecimentos são desenvolvidos, novas posturas são assumidas e o surgimento de um novo ator educacional na sociedade torna-se inevitável.

Consoante a esse fato, a formação ao longo da vida do educador constitui um ato contínuo. O saber-ser e o saber-fazer da profissão se combinam, assim, a uma realidade de transformações que, por sua vez, demanda resolução de problemas em contextos inusitados, os quais não são ensinados e nem fazem parte do composto curricular da maioria dos cursos de formação inicial. Essa realidade requer também um rearranjo fecundo entre os inúmeros saberes que o indivíduo adquiriu por meio dessa experiência abordada, potencializada pela Formação ao Longo da Vida no campo da educação.

É importante também ressaltar que, Libanio (2002, p.13), em suas reflexões sobre o tema da formação, acrescenta que a ideia de formação não parte da "imposição a uma "fôrma", mas de um processo cujo principal protagonista seja a pessoa do formador, com enorme respeito à sua singularidade, a tudo que já é". Tal colocação indica que esse processo educativo pode ser encarado como fonte de renovação do estilo de vida do professor que se dedica a buscar novos horizontes de conhecimento pessoal e profissional. Em suma, é um meio de lutar pela autorrealização na esfera do trabalho e social.

Em referência à construção dos conhecimentos, Meirieu (1998) sublinha que as articulações existentes entre o projeto de vida do trabalhador e as informações fornecidas pelo meio constituem instrumento capaz de emergir a "criação de sentido" no percurso profissional e desse modo, a verdadeira compreensão do que é ensinado. Como a FLV se 
insere na vida do professor dotado de certa experiência profissional, a prática se combina com a teoria a fim de otimizar a aprendizagem.

Para Tomasi e Ferreira (2013, p. 104) a FLV é firmada como "algo que nunca acaba", pois trabalha para manter o aluno (no caso desse trabalho, o professor) cada vez mais "motivado a aprender, sem, contudo, desconsiderar a importância dos seus saberes e da aprendizagem desses saberes." Nessa linha de pensamento, Carvalho (2014) orienta que o desenvolvimento profissional docente é um caminho que não deve ser interrompido porque acolhe a necessidade do professor ao longo de sua carreira em temas como currículo, conhecimento científico-profissional e contextual. $\mathrm{O}$ autor examina tal processo e escreve ainda que:

[...] neste sentido, a formação de professores é encarada como um modo de promover o desenvolvimento profissional, cabendo ao professor tirar partido das oportunidades de formação que correspondam às suas necessidades e objetivos. (CARVALHO, 2014, p.27-28).

Em relação à competência, tentar desenvolvê-la nos agentes é o mesmo que ofertar a eles condições para desenrolar embaraços que possam surgir no ambiente de trabalho, assim como também a capacidade de previsibilidade e preparação. A esse respeito, Costa, Tomasi e Magalhães (2010, p. 976) atestam tal colocação ao afirmarem que "a competência se encontra, também e, sobretudo, nos comportamentos, nas atitudes, que têm como característica fundamental antecipar-se aos problemas, e não apenas, solucioná-los". Deixam claro que essa constatação se dá em meio a uma pane ou ao prolongamento dela no posto de trabalho. Pires (2002) reafirma e acrescenta as situações pelas quais a competência se manifesta:

[...] num contexto de complexidade e de imprevisibilidade, fruto das novas exigências da produção, que os indivíduos mobilizam capacidades de ação (qualidades individuais e conhecimentos adquiridos) para fazer face à complexidade das situações de trabalho. (PIRES, 2002, p. 245)

Dugué (2004) também apresenta uma série de benefícios que a gestão baseada na noção de competência oferece aos profissionais e às organizações. Para isso, estabelece fronteiras entre a qualificação profissional e a noção de competência. Dugué (2004, p. 24) adverte que "o recurso às competências é uma resposta às insuficiências do sistema de qualificação em face das novas condições". A autora entende por "novas condições" a constante atualização do mundo do trabalho. Destaca a importância da competência ao posicioná-la de frente aos certificados profissionais ao afirmar que: "os diplomas validam 
saberes, ao passo que as competências remetem a uma mistura do saber e de comportamento que confere um lugar preponderante aos "saber-ser" e ao investimento psicológico" (Dugué (2004, p. 24)).

Ademais, estudar a Formação ao Longo Vida e suas relações sobre a ótica da consolidação de competências significa construir suporte teórico que conduza professores e sistemas de ensino a juntos seguirem seus objetivos por um meio capaz de reduzir discrepâncias de interesses, uma vez que parte da iniciativa do próprio sujeito para o desenvolvimento do seu trabalho.

\section{Enquadramento do estudo}

Para a prática do trabalho proposto, serão utilizadas pesquisas, de caráter quantitativo descritivo e principalmente qualitativo exploratório entre professores sem curso e egressos de programas de formação continuada para educadores (capacitação, pós-graduação ou até mesmo mestrado), que se apresentarão de modo a estabelecer interfaces com a literatura da área de formação continuada e competência. Assim, a pesquisa se caracteriza como sendo qualitativa e a metodologia adotada se enquadra na concepção de estudo de caso.

O enquadramento da pesquisa nos pressupostos da abordagem qualitativa apoia-se no fato de que esse tipo de investigação "assume que o comportamento humano é significativamente influenciado pelo contexto em que ocorre [...]". (BOGDAN e BIKLEN, 1994, p.48). Por meio dela será possível ouvir o trabalhador que exerce a função docente, bem como registrar seus anseios, suas perspectivas e objetivos. Procurar-se-á entender quais as são os interesses por trás da decisão de formar-se, bem como o crescimento já sentido pelo professor em seu exercício cotidiano.

Assim como se apresenta a premissa do processo de Formação ao Longo da Vida, o professor será colocado no centro de um trabalho que busca compreender a importância da formação na sua estrutura profissional. Ainda segundo esses autores, "os dados recolhidos são em forma de palavras ou imagens e não de números" (BOGDAN e BIKLEN, 1994, p.48). Por esse aspecto da investigação, além da revisão da literatura e da fundamentação teórica pertinente, serão utilizados questionários, por darem margem à característica dialógica que subjaz a abordagem qualitativa, os quais poderão servir para traçar um desenho mais objetivo e ao mesmo tempo aberto no que diz respeito ao agrupamento de motivos impulsionadores à formação contínua.

Segundo Pádua (2008, p.70), a pesquisa do tipo entrevista organiza-se como sendo "um conjunto de questões sobre o tema que está sendo estudado, mas permite, e às vezes até incentiva, que o entrevistado escreva livremente sobre assuntos que vão surgindo como desdobramentos do tema principal." A escolha por questões que dão margem ao diálogo e à 
exploração está também baseada nas considerações de Bordam e Belém (1994) a respeito das estratégias para um pesquisador qualitativista.

A partir dos discursos produzidos pelos entrevistados serão organizadas as categorias de análise. A categorização apresenta-se, de acordo com Pádua (2008, p. 73) embasada a "uma operação de classificação de elementos constitutivos de um conjunto, por diferenciação e, seguidamente, por reagrupamento segundo o gênero (analogia), com os critérios previamente definidos". As categorias podem ser criadas a priori ou definidas posteriormente, a partir das análises das respostas dadas pelos participantes para então serem analisadas segundo a fundamentação teórica.

A pesquisa será realizada com professores de escolas estaduais e municipais de ensino médio situadas na região metropolitana de Belo Horizonte - Minas Gerais.

A análise dos casos registrados será uma importante base para averiguar a dinamicidade da construção de competências pessoais e profissionais, a fim de contribuir para a uma proposta de FLV mais amplamente aplicável ao escopo dos programas pesquisados.

Dito isso, o objetivo central se estabelece em analisar, do ponto de vista do professor, como as interfaces entre o processo de FLV, o desenvolvimento e aperfeiçoamento de competências e de poder de decisão do professor podem colocá-lo no centro do seu trabalho e com isso desenvolver e consolidar suas competências profissionais. Logo, é preciso cultivar a autonomia docente como alicerce de um programa de desenvolvendo pessoal que, por sua vez, atingirá diretamente o êxito nos processos pedagógicos de aprendizagem nos sistemas educacionais.

\section{Resultados esperados}

A nossa expectativa é que essa pesquisa evidencie formas prototípicas que nos possibilitem identificar e categorizar as possíveis ações de valorização e de investimento na formação do professor de modo a permitir-nos associá-los com as trajetórias profissionais e com os mundos vivenciados no trabalho.

A nossa hipótese é que poderemos identificar predisposição para a formação ao longo da vida subjacente às representações das expectativas sociais e profissionais relativas às perspectivas futuras quanto ao mundo do trabalho em que pesem as possibilidades de formação continuada e de valorização profissional resultante dessa formação.

Em se confirmando a nossa expectativa, estaremos diante de questões relacionadas ao conhecimento que em geral são desconsideradas ou negligenciadas nas políticas públicas e nas pesquisas com foco na formação e na aprendizagem ao longo da vida. Nesse caso, 
poderemos trazer contribuições à FLV por meio da problematização dos fatores intervenientes nas políticas de investimentos e de valorização dos profissionais da educação em serviço.

\section{Referências}

BOGDAN, Robert. e BIKLEN, Sari Knopp. Investigação qualitativa em educação: uma introdução à teoria e aos métodos. Porto Editora, 1994.

CARVALHO, Ana Isabel Machado. Desenvolvimento profissional de professores: Especificidades na transição para a Formação de Adultos. Dissertação de Mestrado em Ciências da Educação - Área de Especialização em Formação de Professores - Universidade de Lisboa, p. 27-28, Lisboa: 2014.

COSTA, Joselane Cavalcante; TOMASI, Antônio de Pádua Nunes; MAGALHÃES, MaqGeisielly Alves. A mobilização de saberes na formação dos trabalhadores da construção civil. International Conference on Engineering and Technology Education, Ilhéus, BRAZIL, 2010.

DUGUÉ, Elisabeth. A lógica da competência: o retorno ao passado. In: TOMASI, Antônio de Pádua Nunes (Org). Da Qualificação à Competência. Campinas: Paripus: 2004, cap. 1.

FERREIRA, Jane Eyre Rios de Macêdo. A Formação ao Longo da Vida - (FLV). Um estudo sobre a formação profissional de trabalhadores da construção civil. Dissertação de Mestrado em Educação Tecnológica. - Centro Federal de Educação Tecnológica de Minas Gerais - CEFET-MG, 2012.

JUNIOR, João Batista Bottentuit; COUTINHO, Clara Pereira. A educação a distância para a formação ao longo da vida na sociedade do conhecimento. Instituto de Educação e Psicologia da Universidade do Minho - Braga - Portugal, 2007.

LIBANIO, João Batista. A arte de formar-se. São Paulo: Loyola, 2002.

MEIRIEU, Philippe. Aprender... sim, mas como? 7. ed. Porto Alegre: Artes Médicas, 1998. MERLE, Vicent. Apprendre tout au long de la vie: pourquoi, comment? Comité Mondial pourl'éducation et la formation tout au long de la vie. Paris: UNESCO, 2006.

NÓVOA, A. Os Professores e a sua Formação. Lisboa: Dom Quixote. ISBN 972-20-10085. pp. 13-33. Disponível em: http://hdl.handle.net/10451/4758 (consultado a 21 de setembro de 2017). 1992.

PÁDUA. Elisabete Matallo Marchesini de. Metodologia da Pesquisa: Abordagem teóricaprática. 10ª Ed. Campinas: Papirus, 2008.

PIRES, Ana Luisa de Oliveira. Educação e Formação ao Longo da Vida: análise crítica dos sistemas dispositivos de reconhecimento e validação de aprendizagens e de 
competências. Tese (Doutorado) - Universidade Nova de Lisboa, Faculdade de Ciências e Tecnologia. Lisboa: 2002.

SOUZA, João Valdir Alves de. A dimensão formativa do trabalho. Publicado em: NOGUEIRA, Maria das Dores $P$ (Org.) Vale do Jequitinhonha: ocupação e trabalho. Belo Horizonte: PROEX/UFMG, 2013.

TOMASI, Antônio de Pádua Nunes; FERREIRA, Jane Eyre Rios de Macêdo. Formação ao Longo da Vida (FLV): o que o trabalhador quer aprender? 2013. 